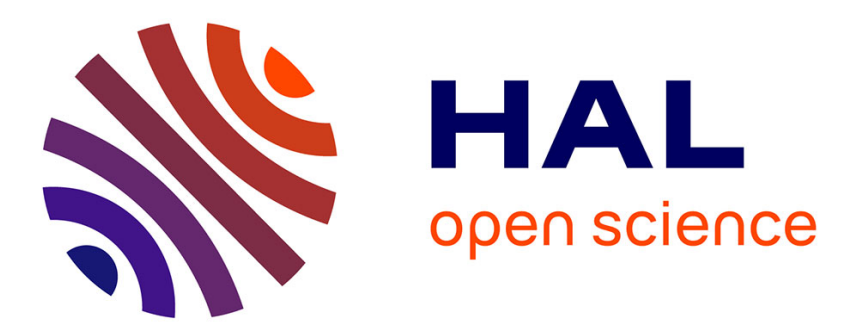

\title{
Performance of lightweight mortar reinforced with doum palm fiber
}

Fatma Naiiri, Allègue Lamis, Mehdi Salem, Redouane Zitoune, Zidi Mondher

\section{To cite this version:}

Fatma Naiiri, Allègue Lamis, Mehdi Salem, Redouane Zitoune, Zidi Mondher. Performance of lightweight mortar reinforced with doum palm fiber. Journal of Composite Materials, 2021, 55 (12), pp.1591-1607. 10.1177/0021998320975196 . hal-03040724

\section{HAL Id: hal-03040724 https://imt-mines-albi.hal.science/hal-03040724}

Submitted on 4 Dec 2020

HAL is a multi-disciplinary open access archive for the deposit and dissemination of scientific research documents, whether they are published or not. The documents may come from teaching and research institutions in France or abroad, or from public or private research centers.
L'archive ouverte pluridisciplinaire HAL, est destinée au dépôt et à la diffusion de documents scientifiques de niveau recherche, publiés ou non, émanant des établissements d'enseignement et de recherche français ou étrangers, des laboratoires publics ou privés. 


\title{
Performance of lightweight mortar reinforced with doum palm fiber
}

\author{
Fatma Naiiri $^{1,2}$ (D, Allègue Lamis', Salem Mehdi², \\ Zitoune Redouane ${ }^{2}$ and Zidi Mondher'
}

\begin{abstract}
Natural fibers are increasingly used in composites because of their low cost and good mechanical properties. Cement reinforced with natural fibersis contemplates as a new generation of construction materials with superior mechanical and thermal performance.

This study of three sizes'effect of Doum palm fiber explores the mortar's behavior reinforced with different fiber ratio. The aim is to determine the optimal addition to improve mechanical and thermal properties of natural fiber reinforced cements. Physical, mechanical and thermal properties of composite are examined. Tensile properties of Doum fibers are verified to determine their potential as reinforced material. Findings prove that the use of alkali-treated Doum fiber as reinforcement in cement mortar composite leads to the upgrading of the mechanical properties including thermophysical properties against composites reinforced with raw fibers and control cement mortars. While, the compression and flexural strength of the cement mortar reinforced with alkali-treated Doum fiber with diameter $0.3 \mathrm{~mm}$ (CT3) are metered to be II.I I MPa, 5.22 MPa, respectively for fiber content $0.5 \%$. Additionally, based on thermo-physical tests, it is assessed that the thermal conductivity and diffusivity decrease for cement mortar reinforced with Doum fiber with diameter $0.2 \mathrm{~mm}$ (CT2).
\end{abstract}

\section{Keywords}

Cement mortar, doum palm fiber, treatment, mechanical properties, thermal properties

\section{Introduction}

Owing to rapid urbanization, buildings are designed without taking into account their environment. Standard mortar is deemed as an important construction material, it is gradually spent for civil infrastructure all over the world, which has poor thermal insulation properties. Contrary to vernacular and traditional buildings where people used to build their houses using natural materials.

Frequently used construction materials, including synthetic fibers, increase pollution, regarding their disposal environmental issues and $\mathrm{CO} 2$ manufacturing emission. ${ }^{1}$

Industries have recently been focusing on the development of lightweight and eco-friendly construction materials. ${ }^{2}$ Therefore, they have marked an awareness to limit the use of cement reinforced with synthetic fibers. For this reason, researchers have records to innovate sustainable materials to replace synthetic fibers by natural fibers as reinforcement of structural materials. $^{3}$

Many researchers deal with the use of palm fibers as reinforcement in constructions materials due to their important insulation properties. Mansour et al. ${ }^{4}$ investigated the effect of rachis and petiole of palm trees on compressive, flexural strength and thermal conductivity of cement mortar.

Agoudjil et al. ${ }^{5}$ highlighted that the date palm waste is a good product for the development of safe and efficient insulating materials. For this purpose, Chikhi et al. ${ }^{6}$ studied a new biocomposite material alaborated

\footnotetext{
'Laboratory of Mechanical Engineering, National School of Engineering of Monastir, University of Monastir, Tunisia

${ }^{2}$ Institut Clément Ader (ICA), CNRS UMR 53I2, France
}

\section{Corresponding author:}

Fatma Naiiri, Laboratory of Mechanical Engineering, University of Monastir, National School of Engineering of Monastir 5000, Tunisia.

Email: mondher.zidi@enim.rnu.tn 
with date palm fbers and gypsum. The fibers were obtained by grinding the date palm waste wood. These authors publicized that this type of biocomposite exhibits good mechanical and thermal performances, which allows for being appropriate for thermal insulation in building. In a similar way, Benmansour et al. ${ }^{7}$ investigated the use of new material composed of mortar reinforced with date palm fibers. The authors underlined that using these fibers reduces the density and the thermal conductivity of this kind of bio composite. Relating to RILEM classification, ${ }^{8}$ these bio composite materials (according to the concentration and fibers size) can satisfy both mechanical and thermal requirements of lightweight concrete.

Another disadvantage of standard mortar is the fact that it has an elastic deformation followed by a sudden fracture. They do not have a post cracking ductility. ${ }^{1}$

Natural fibers, such as hemp, palm, coconut, and cotton have been examined as potential alternative for synthetic fibers in accord with their low cost and availability in fibrous form.

By focusing our attention on the natural fibers, several studies in the similar field are those by Savastano et al. ${ }^{7,9-11}$ who determines elastic modulus, flexural strength and toughness of cement matrix, alternatively reinforced with banana, eucalyptus or sisal pulps fibers. They draw attention to the fact that by adding $8 \%$ of fibers to the mix, the properties mentioned above increase, compared to the reference mixture. They also show a decrease in the workability of cement reinforced with coir or eucalyptus pulp. This decrease in workability is the result of moisture absorption by natural fibers.

The result of Ramakrishna ${ }^{12}$ reports that the impact resistance of mortar reinforced with plant-fiber are from 3 to 18 times higher than unreinforced mortar. However, the addition of microfibers also reveals a decrease in the compressive strength of the mix that is relative to plain mortar due to the increase in the air content of the mixture.

Compared to composite without fibers, Mansour and Azur ${ }^{13}$ show a decrease in the mechanical properties of composites reinforced with jute fibers as the content and length of fibers'decrease.

However, in spite of the natural fiber advantage, their usefulness as reinforcement of a cement matrix, are restricted by their degradation in an alkaline environment which conducted to, a loss of the composite strength. ${ }^{9,11}$ This problem presents an important matter which needs to be solved before the commercialization of natural fiber as reinforcement for cement matrix in industries.

On the other hand, mechanical properties of composites depend on the adhesion between fibers and matrix. The higher water absorption of natural fibers linked to their dimensional variations leads to forming to voids and micro-cracking at the interfacial transition zone, which results in the reduction of the interfacial adhesion between cementitious matrix and fiber. ${ }^{14,15}$ It is obvious that producing composite with higher mechanical properties from adding natural fiber is definitely linked to good adherence between the matrix and the fiber. Natural fiber has different chemical structures which induces to an inefficient transfer of stress to .the interface. For all these findings, treatment of the fiber surface becomes a requirement. ${ }^{16}$

For all these reasons, in order to improve the interfacial adhesion between the matrix and fiber and to minimize the absorption of water, numerous researchers have used different chemical pretreatments of the fibers. ${ }^{17-20}$

Among these treatments, using alkaline treatment with Sodium hydroxide solution $(\mathrm{NaOH})$ removes the amorphous materials, such as lignin, hemicellulose, pectin and waxes from the outer surface of the fiber. This treatment increases the degree of the fiber's crystallinity and its surface roughness. ${ }^{21}$

Fantilli et al. ${ }^{22}$ experimentally investigates mortar reinforced with both raw and treated wood fibers, by evaluation flexural strength, fracture toughness, and elastic modulus. They find a remarkable increase of the mechanical properties by adding $1 \%$ of treated wood fibers by volume, with an increase of fracture toughness equal to $300 \%$ compared to plain mortar.

Doum palm trees are abundant in Tunisia. A mature palm tree has generally64-128 leaves with fibers and spines on the petiole and renews 10-30 leaves every year.

In this context, this paper primarily provides new information about the Doum palm fibers and presents a variety of results on the effect of $\mathrm{NaOH}$ treatment of Doum palm fibers, like,

Fourier-transform infrared spectroscopy (FTIR), $\mathrm{X}$-ray diffraction (XRD) and mechanical properties. The alkali treatment proves itself to be effective toupgrade the physical and mechanical properties of Doum palm fibers, and as such improving fibers matrixinterface interaction. Elsewhere, the effectiveness of alkali-treated Doum palmon the compressive strength and thermal properties has been discussed.

\section{Materials}

\section{Presentation of doum palm fiber}

The doum palm is composed of a long brunch, a mesh surrounding the trunk, leaves (containing Petiole and Feliole) and fruit brunch.

The doum palm is commonly founded in North Africa and grows up to $17 \mathrm{~m}$. In Tunisia, this tree is 
used as a decorative plant in urban and rural areas and the annual trimming operation generates tremendous quantities of agricultural waste, which are usually discarded.

These wastes can represent a plentiful source of lowcost material for industrial uses. Thus, the development of cement mortar reinforced with this abundant material depict a great solution for the economical utilization of the same wastes as a renewable resource.

The Doum palm fiber is a natural fiber extracted from the petiole of Doum palm which is harvested in Tunisia (Figure 1).

Firstly, petiole is crushed using grinder made in a mechanical engineering laboratory of the national engineering school of Monastir. Secondly, the fiber is screened using different meshes of the grid. From this method, a fiber with diameter varies from $90 \mu \mathrm{m}$ to $500 \mu \mathrm{m}$ is obtained (Figure 2).
Extracted fiber is washed to remove impurities and residues. The washing processes are important to enhance fiber durability because residues can induce the development of fungus on the fiber surface which decreases their utility.

Alkali treatment's objective is to remove lignin and hemicellulose from the fiber wall and enhance surface roughness which has a positive impact on the fibermatrix bond. ${ }^{23}$ The treatment decreases the degree of crystallinity and polymerization as well as the destruction of structural linkage between cellulose and lignin and decomposition of the lignin structure. ${ }^{24}$

Collected fiber is screened using different normalized meshes of the grid. Three types of fiber sizes were obtained; they are listed and presented in Figure 3

- Reinforcement sieve1 with $0.1 \mathrm{~mm}$ mesh noted (RS1) (a)

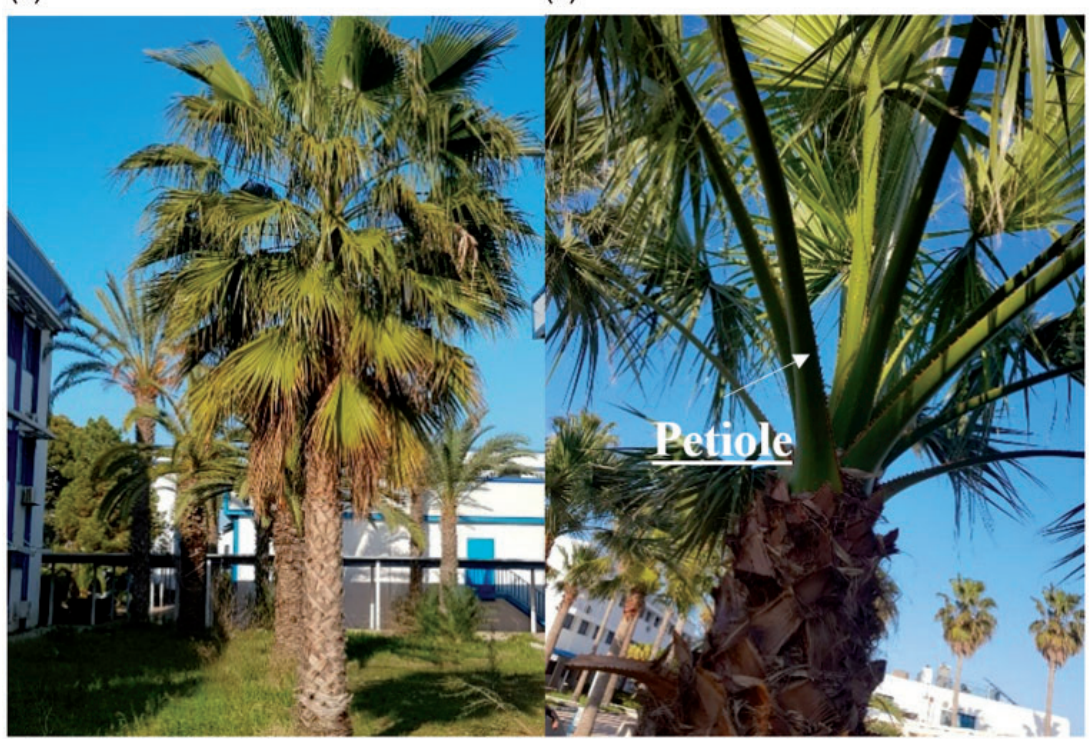

Figure I. Doum palm: With (a) palm tree, (b) palm petiole.

(a)

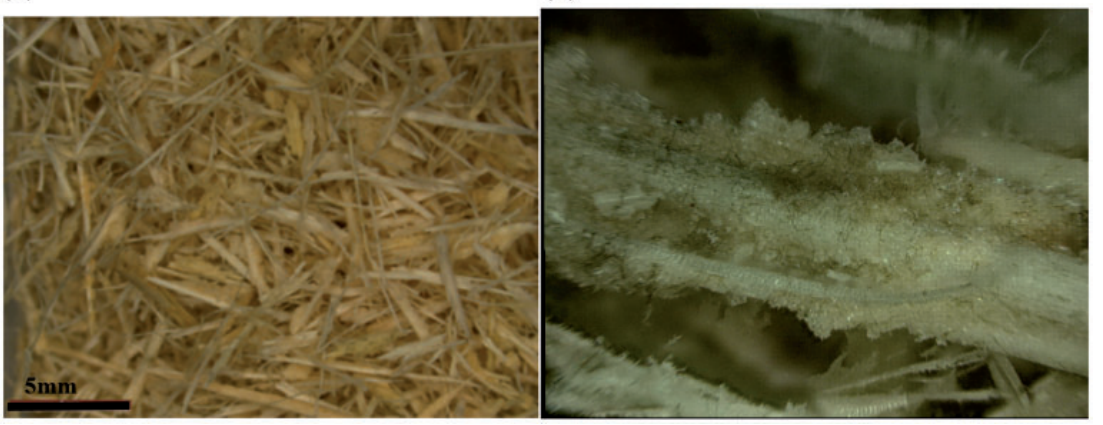

Figure 2. Digital microscope of raw Doum fiber. 

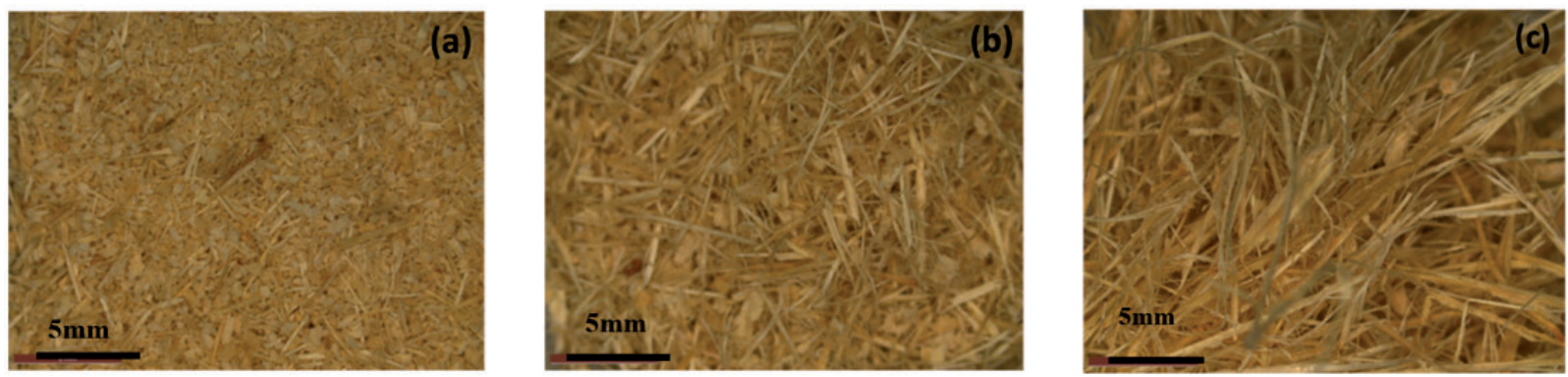

Figure 3. Pictures showing the three kinds of Doum palm fibers with: (a) fibers referenced under RSI, (b): fibers referenced under RS2 and (c): fibers referenced under RS3. ${ }^{25}$

Table I. Cement characteristic.

\begin{tabular}{llllllll}
\hline $\mathrm{CaO}(\%)$ & $\mathrm{SiO}_{2}(\%)$ & $\mathrm{Al}_{2} \mathrm{O}_{3}(\%)$ & $\mathrm{Fe}_{2} \mathrm{O}_{3}(\%)$ & $\mathrm{MgO}(\%)$ & $\mathrm{K}_{2} \mathrm{O}(\%)$ & $\mathrm{Na}_{2} \mathrm{O}(\%)$ & $\mathrm{SO}_{3}(\%)$ \\
\hline 60 & 17 & 4 & 3 & 5 & $\mathrm{I}$ & $\mathrm{I}$ & 3.5 \\
\hline
\end{tabular}

- Reinforcement sieve2 with $0.2 \mathrm{~mm}$ mesh (RS2)

- Reinforcement sieve3 with $0.3 \mathrm{~mm}$ mesh (RS3)

\section{Fiber treatment}

The main component of natural fiber is crystalline cellulose. It also contains lignin, hemicellulose and wax substance. Nevertheless, hemicellulose and lignin can degrade over time. Accordingly, to enhance the longterm durability of cement mortar reinforced with natural fiber and to raise interfacial bonding, an alkali fiber treatment with $\mathrm{NaOH}$ solution can be employed.

Hemicellulose which mainly consists of hexosan, xylan, andpolyuronide, is very delicate to the action of caustic soda. Thus, alkali fiber treated with $\mathrm{NaOH}$ can enhance adhesion characteristics of natural fiber by striking out pectin, hemicellulose, and lignin consequently giving to the fiber a rough surface.

The major modification in this treatment is the removal of hydrogen bonding from the structure. The reaction, that takes place between fiber and alkali treatment, is presented in the following equation (1):

$$
\text { Fiber }-\mathrm{OH}-\mathrm{NaOH} \rightarrow \text { Fiber }-\mathrm{O}-\mathrm{Na}+\mathrm{H}_{2} \mathrm{O}
$$

The Doum palm fiberwas treated using $1 \mathrm{wt} \%$ hydroxide sodium in water. They are soaked in the alkaline solution for 1 hour at temperature $105^{\circ} \mathrm{C}$. Subsequently, the alkalized fiber is washed using distilled water until it eliminates all the residues of the sodium hydroïde. Afterward, the washed fiber is bleached with sodium chloride and finally washed with distilled water. ${ }^{25}$

\section{Cement}

A Portland cement CEMII $32.5 \mathrm{R}$ is used for all mixture, produced by Carthage Company of Tunisia conforming to ASTM C1329 - 05 requirements. ${ }^{26}$

The chemical compositions are shown in Table 1.

Portland cement presents an alkali environment because it contains important quantities of $\mathrm{CaO}$ (Table 1). When it reacts with water it produces a solution oversaturated by $\mathrm{Ca}(\mathrm{OH})_{2},(\mathrm{CH})$ and small percentages of $\mathrm{Na}_{2} \mathrm{O}$ and $\mathrm{K}_{2} \mathrm{O}$ which forms $\mathrm{NaOH}$ and $\mathrm{KOH}$ solutions.

\section{Sand}

Rolled sand with granulomere $(0 / 2)$ is used in the experiments according to ASTM C348 requirements. ${ }^{27}$ It is purchased from the quarries of the National company of Granulats Jbel OUST (GJ) in Jabal OUEST Tunisia.

The cumulative percentage graph of sand is given in Figure 4.

After analysis, the values appeared are tabulated below Table 2 .

$\mathrm{FM}=2.315$

The fineness modulus of fine aggregate is 2.315 . It means that the average aggregate size is between 2.2-2.8. The used sand is preferential sand according to Standard NF $18-540 .{ }^{28}$

\section{Composite preparation}

The operating procedure for the manufacture of mortar consists of manufacturing traditional mortar (a mixture of sand,cement and water) and after adding different length of Doum palm fibers. For the 


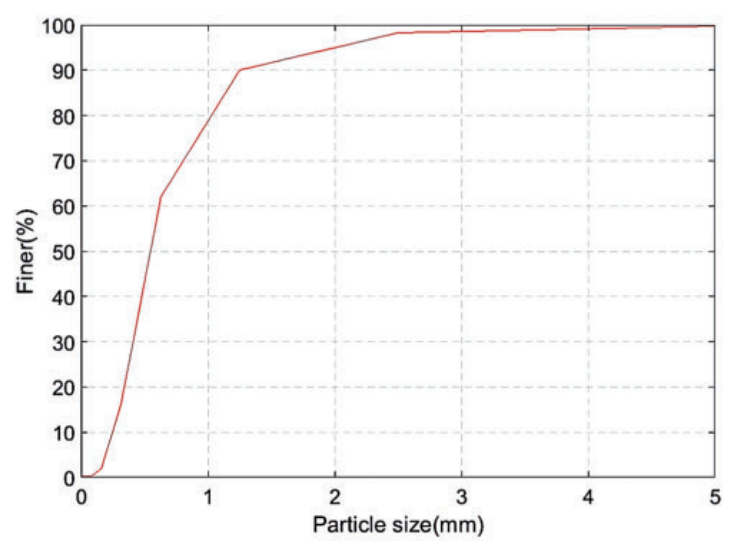

Figure 4. Grain size distribution. preparation of composite, mixing is executed using an automatic mortar mixer with maximum capacity 51 .

Figure 5 illustrates the used method to prepare the composite.

To minimize the absorption of water by fibers, fibers are soaked in $10 \%$ of water. In preparation of mixtures, firstly sand with $30 \%$ of water is added to the mixing container. The mixture is started to be mixed at low speed for 30 seconds. After those fibers with $30 \%$ of water are gradually added to the mixture to avoid the grouping of the fibers and also the abrupt absorption of large quantities of water. The mixer is stopped in $30 \mathrm{~min}$. Finally, cement and water are continuously added and the mixer is adjusted to high speed.

Table 2. Values after analysis.

\begin{tabular}{lccc}
\hline Sieve size & $\begin{array}{l}\text { Weight } \\
\text { retained }(\mathrm{g})\end{array}$ & $\begin{array}{c}\text { Cumulative weight } \\
\text { retained }(\mathrm{g})\end{array}$ & $\begin{array}{c}\text { Cumulative percentage } \\
\text { weight retained }(\%)\end{array}$ \\
\hline 5 & 0.5 & 0.5 & 0.25 \\
2.5 & 3 & 3.5 & 1.75 \\
1.25 & 16.5 & 20 & 10 \\
0.63 & 56 & 76.0 & 38 \\
0.315 & 91.5 & 167.5 & 83.75 \\
0.16 & 28.5 & 196.0 & 98 \\
0.080 & 3.5 & 199.5 & 99.075 \\
Bottom & 0.5 & 200 & 100 \\
\hline
\end{tabular}

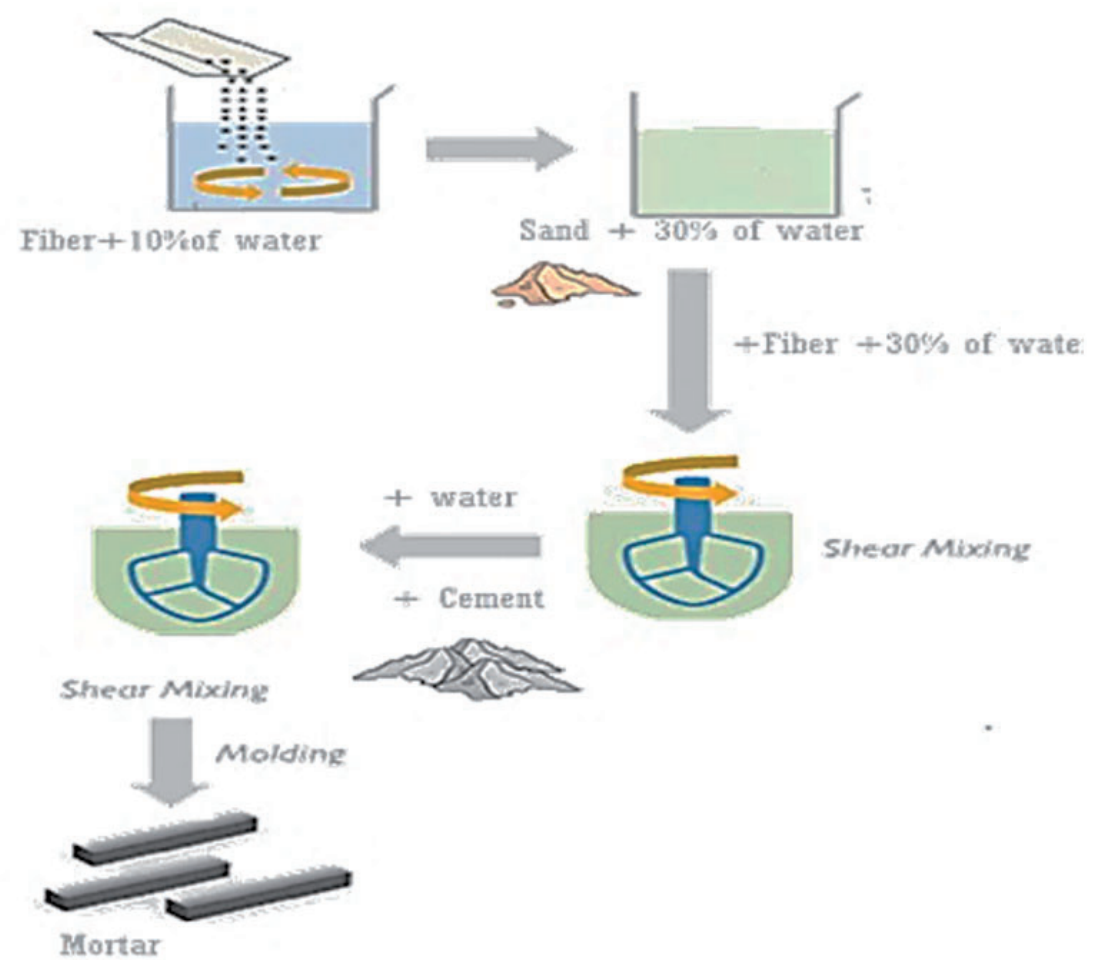

Figure 5. Schematic representation of the manufacturing process for cement mortars. 
Table 3. Mix proportion of the cement mortar $\left(\mathrm{Kg} / \mathrm{m}^{3}\right)$.

\begin{tabular}{lllll}
\hline $\begin{array}{l}\text { Fiber } \\
\text { ratio } \%\end{array}$ & $\begin{array}{l}\text { Cement } \\
(\mathrm{Kg})\end{array}$ & $\begin{array}{l}\text { Sand } \\
(\mathrm{Kg})\end{array}$ & $\begin{array}{l}\text { Water } \\
(\mathrm{Kg})\end{array}$ & $\begin{array}{l}\text { Fibers } \\
(\mathrm{Kg})\end{array}$ \\
\hline 0 & 450 & 1350 & 225 & 0 \\
0.5 & 450 & 1350 & 250 & 10.12 \\
1 & 450 & 1350 & 265 & 20.25 \\
1.5 & 450 & 1350 & 300 & 30.37 \\
2 & 450 & 1350 & 300 & 40.49 \\
2.5 & 450 & 1350 & 300 & 50.625 \\
\hline
\end{tabular}

The mixer is stopped after $2 \mathrm{~min}$ and $30 \mathrm{~s}$ and the adhered mortar to walls is scratched by scraping. The obtained mortar is placed into $4 \mathrm{~mm} \times 4 \mathrm{~mm} \times 16 \mathrm{~mm}$ dimensions molds.

Firstly, the half volumes of molds arre filled with mortar and are shacked using a shaking table for $30 \mathrm{~s}$. After that, the molds are filled and shacked for another 30 seconds. The specimens are unmolded after 24 hours and they are cured under laboratory conditions for 28 days. Each experimental test is repeated 3 times.

The proportions of materials for the reference mortar was one part of cement to 3 parts of sand by weight with 0.5 water-cement ratio. For the reinforced specimens, the quantity of water is adjusted to have the same workability as the reference mortar

To study the effect of the quantity of fibers added to cement in the composite properties, a five-weight fraction of Doum palm fiber is used from $0.5 \%$ to $2 \%$ with a step of $0.5 \%$. We notice that we used untreated and treated fibers for all the study.

Natural fiber presents a sensibility to the alkalinity of cement. To remedy this problem, doum fiber is treated with $1 \% \mathrm{NaOH}$ solution for 1 hour at a temperature of $105^{\circ} \mathrm{C}^{25}$

The details of the mix proportions per cubic meter for all composites are presented in Table 3.

The designations of the various cement mortars are presented in Table 4.

\section{Experimental methods}

\section{Fiber chemical composition properties}

To enhance and develop better evaluations of Doum fiber and their capacity, many factors are determined for their selection as reinforcement in the bio-based material. The considered evaluation criteria includes chemical, physical and mechanical tests are evaluated.

The cellulose, hemicellulose and lignin contents are calculated by the traditional Van-Soest method (Figure 6). ${ }^{29}$ Doum powder of $0.50 \mathrm{~g}$ is properly weighed for the chemical measurement. The chemical measurements are repeated for three sample with a relative error lower than $5 \%$.
Table 4. Composite designation.

\begin{tabular}{ll}
\hline Mix type & Matrix \\
\hline RCM & Reference cement mortar \\
CNTI & Cement mortar + untreated fiber sieve I \\
CNT2 & Cement mortar + untreated fiber sieve 2 \\
CNT3 & Cement mortar + untreated fiber sieve 3 \\
CTI & Cement mortar + treated fiber sieve I \\
CT2 & Cement mortar + treated fiber sieve 2 \\
CT3 & Cement mortar + treated fiber sieve 3 \\
\hline
\end{tabular}

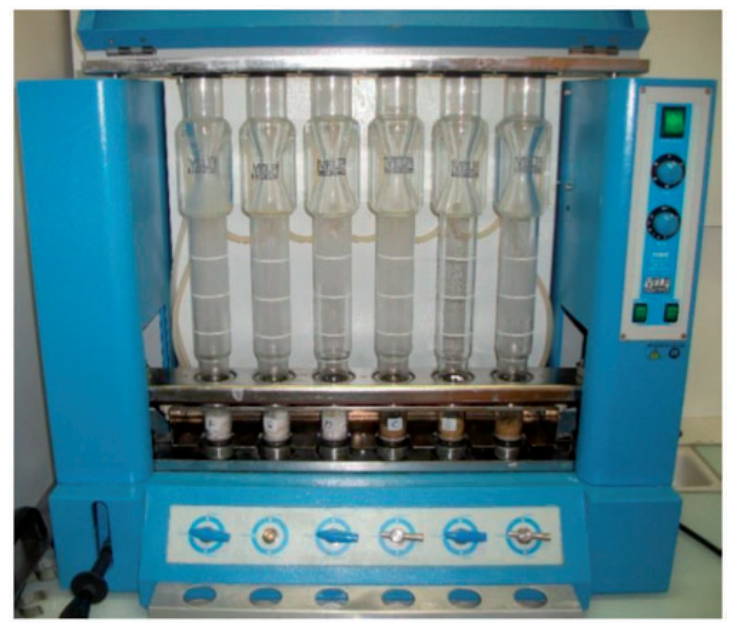

Figure 6. Van-Soest method.

\section{Water capacity absorption}

In order to measure the water absorption capacity of raw and treated fiber, a procedure inspired by the German codex's STN2: 117/87 standard is used.

In practice: a selected mass of each sample is dried in the oven until its mass is constant. The sample is then placed in a hydrophobic veil bag (the weight of which is well known in advance) and weighed $\left(\mathrm{M}_{0}\right)$. Then immersed in distilled water for 30 minutes at room temperature. The sample is then drained for 5 minutes and weighed again $\left(\mathrm{M}_{1}\right)$.

Water absorption capacity is determined by the following formula:

$$
\frac{M_{1}-M_{0}}{M_{1}}(\mathrm{~g} / \mathrm{g})
$$

\section{X-ray diffraction}

The crystallinity of fiber is studied by X-Ray diffraction (XRD). The XRD analysis of Doum palm fiber is carried out using a D8 advance diffractometer.

Diffraction diagrams are monitored by recording X-ray diffraction patterns between $0^{\circ}$ and $70^{\circ}(2 \theta$ angle range). 
The crystallinity index $\left(I_{C}\right)$ is calculated using the following expression used by Segal ${ }^{30}$ (equation (2))

$$
I_{C}=\frac{I_{002}-I_{a m}}{I_{002}} \times 100
$$

$\mathrm{I}_{002}$ is the maximum intensity of diffraction of the $(0$ 0 2) lattice peak $2 \theta$ between $22^{\circ}$ and $23^{\circ}$, and $I_{a m}$ is the intensity of diffraction of the amorphous material, which is taken at $2 \theta$ angle between $18^{\circ}$ and $19^{\circ}$ where the intensity is at a minimum. ${ }^{31}$

\section{Scanning electron microscopy image}

The scanning electron microscopy (SEM) is used to examine the influence of chemical treatment on the surface morphology of Doum palm fiber and the interfacial properties of Doum mortar composites.

The microscopic examinations are performed using scanning electron microcopy type HITACHI-TM3030 which provides magnifications up to 60.000 times. The accelerating voltage is $15 \mathrm{kV}$ and $5 \mathrm{kV}$. This test is realized in the Roberval laboratory, Compiegne University of Technology in France.

\section{Density in hardened states}

Bulk density is measured in hardened state, according to EN1015-10, using $40 \mathrm{~mm} \times 40 \mathrm{~mm} \times 160 \mathrm{~mm}$.test. specimens, following 28 days of curing at a temperature of $20 \pm 1{ }^{\circ} \mathrm{C}$, at a relative humidity of $65 \pm 5 \%$.

\section{Composite mechanical properties}

Specimens are removed from molds after 24 hours and are left under normal conditions (Temperature $\mathrm{T}=20 \pm 2^{\circ} \mathrm{C}$ and relative humidity $\mathrm{RH}=65 \pm 5 \%$ ) during 28 days until testing.

Compressive strength and flexural strength.were measured at 28 days,.as per Standard EN 1015-11, ${ }^{32}$ usinga LLYOD.equipped with a $20 \mathrm{KN}$ load cell. Three different test specimens are tested.under flexion for each combination.and six under compression. The test specimens measured $40 \mathrm{~mm} \times 40 \mathrm{~mm} \times 160 \mathrm{~mm}$. and the bottom support rollers.are separated at intervals of $100 \mathrm{~mm}$.

The flexural strength is calculated through the following relationship (equation (3)) according to NF EN 12390-3 standard. ${ }^{33}$

$$
\sigma=\frac{3 F L}{2 w h^{2}}
$$

Where $L$ is span length, $w$ is the width of the specimen, $F$ is applied load and $h$ is the thickness of the specimen.
The compressive strength is calculated with this formula (equation (4)):

$$
\sigma_{c}=\frac{F_{c}}{S}
$$

Where $F$ is the load and $S$ is the section of the applied force.

\section{Thermal conductivity}

All thermo-physical tests of composites are performed using samples with dimensions of $4 \times 2 \times 1 \mathrm{~cm}^{3}$.

The thermal conductivity and diffusivity are determined using the Hot disk method TPS $2500 \mathrm{~S}$ with a precision of $5 \%$ under the following climatic conditions: $\mathrm{T}=21 \pm 2^{\circ} \mathrm{C}$ and relative humidity $\mathrm{RH}=$ $45 \% \pm 10 \%$.

The hot disk technique is used for a transient measurement of thermal conductivity and thermal diffusivity. It consists of fitting the sensor between two pieces sample, each one with a plane surface. The sensor used in this test method is made of nickel foil, which is wound in a double spiral pattern with a 6.403 radius.

For all specimens, each measurement is relative to three similar tests.

To estimate the potential of composite for building, the thermal diffusivity is calculated using the following (equation (5)):

$$
a=\frac{\lambda}{\rho c}
$$

Where $\lambda$ is the conductivity ( $\mathrm{W} / \mathrm{m} \mathrm{k}), \rho$ is the density $\left(\mathrm{Kg} / \mathrm{m}^{3}\right)$ and $c$ is the specific heat $(\mathrm{J} / \mathrm{kg} \mathrm{K})$

\section{Results and discussions}

\section{Fiber chemical composition properties}

To study the effect of $\mathrm{NaOH}$ treatment on the mechanical and physical properties of fiber, many tests are carried out on the raw and the treated fiber. The results were presented previously by Naiiri et al. ${ }^{25}$

The $\mathrm{NaOH}$ treatment leads to a reduction of the fiber diameter with a decrease of the density by removing the lighter compounds from its surface.

An important amelioration of the mechanical properties and tensile strength is noted due to the higher homogeneity inside the fibers. ${ }^{25}$

The chemical characterization of raw Doum fiber as shown in Table 5 prove that it contains cellulose $(42.3 \%)$, hemicellulose $(21.85 \%)$, lignin $(18 \%)$. It also reveals that the pectin and protein content is $5.51 \%$ and moisture $17.61 \%$. 
Table 5. Various properties of the commonly used fibers compared with used fiber in this study.

\begin{tabular}{lllll}
\hline Type of fiber & Doum palm fiber & Date palm fiber & Flax & Hemp \\
\hline Cellulose (\%) & 42.3 & 46 & $62-72$ & $68-74.4$ \\
Hemicellulose (\%) & 21.85 & 18 & $18.6-20.6$ & $15-22.4$ \\
Lignin (\%) & 18 & 20 & 2.3 & $3.7-10$ \\
Pectin and protein (\%) & 5.51 & & $88-12$ \\
Moisture content (\%) & 17.61 & $5-21.1$ & $1.2-3.3$ & $6.2-12$ \\
Elongation at break (\%) & 7.89 & $2-19$ & $343-2000$ \\
Tensile strength (MPa) & 155.88 & $97-275$ & Salit et al. ${ }^{35}$ & $270-900$ \\
Reference & This study and Fatma et al. ${ }^{25}$ & Hamza et al. ${ }^{34}$ & Li et al. $^{36}$ \\
\hline
\end{tabular}

It can be concluded that fiber with higher cellulose contents has better mechanical properties. Hemp and flax have relatively higher values of tensile strength than the date and Doum palm fiber as they have higher cellulose content. On the other hand, the quantity of cellulose hurts the fiber elongation to break property. From this table, results reveal that Doum and date palm fiber have a better elongation to break characteristics due to their lower content of cellulose.

\section{Absorption capacity}

Absorption capacity being the amount of liquid remaining associated with the sample after impregnating and draining.

The absorption capacity of alkali-treated fiber increasing from $0.52 \mathrm{~g} / \mathrm{g}$ to $0.71 \mathrm{~g} / \mathrm{g}$, a result that confirm that treated fibers have interesting hydrophilic traits due to the elimination of hydrophobic materials and the increase in hydroxides.

\section{X-ray diffraction method}

An alkaline treatment using a $\mathrm{NaOH}$ solution is frequently used to increase the crystallinity index of natural fiber.

This index is related to the arrangement of cellulosic chains. The removal of an amorphous constituent from the surface of the fiber provides an increase of the crystallinity index and accordingly of the cellulosic chains. The X-ray diffraction patterns of Doum palm fiber are shown in Figure $7 .{ }^{37}$ The major crystalline peak occurs at around $2 \theta=22.4^{\circ}$, which represents the cellulose crystallographic plane $\left(\begin{array}{lll}0 & 0 & 2\end{array}\right)$. In our case, a pronounced peak at $22.5^{\circ}$ is observed.

After the treatment, the main peak is increased which translates to an increase in the degree of crystallinity of the fiber during their immersing. ${ }^{37}$

Alkali treatment leads to the elimination of amorphous or poorly crystallized constituent for the fibers. The estimated values for treated and untreated Doum palm fiber are presented in Table 6 .
Thus, the presence of important quantities of amorphous elements inducing spaces and disoriented areas could negatively influence the crystallinity index of fiber. ${ }^{38}$

When fibers contain large quantities of amorphous material, the two-diffraction peak around $14.8^{\circ}$ and $16.4^{\circ}$ correspond to the (101) and (101) crystallinity planes appears as one broke peak. From Figure 7 we can observe that these two peaks are more defined for the treated Doum palm fibers than for the untreated fibers. It is in accord with the increase of the crystallinity index presented in Table 6 .

\section{Morphological characterization of fibers}

Knowledge of fiber morphology is important because it provides information on the interfacial adhesion between the fibers and the matrix. To characterize the morphology of Doum palm fibers, a HITACHI TM3030 scanning electron microscopy (SEM) and Keyence Digital Microscope VHX 2000 are used.

Figure 8 represents the longitudinal views of Doum palm fibers. They show that they have irregular shapes covered with a layer of gummy and waxy substances. Their structure is similar to natural composites.

The cellulose fibrils are held together by lignin and hemicellulose to form fibers. For plants, the fibers are linked together by lignin which has a high solubility in the alkali environment of the matrix.

A cross section of petiole fiber (Figure 9) shows the presence of many numbers of hollow single fibers bonded by a layer. Elsewhere, the shape and the structure of petiole Doum palm fiber are similar to the most natural fiber and particularly to the coir fiber. ${ }^{39,40}$

Each fiber is cylindrical in shape and formed with multicellular fibers each containing a central void (lumen). According to morphological studies performed on palm fiber, Agoudjil et al..$^{5}$ predict that the external layer can be lignin and the withdraw of this layer lead to a stable bond between the fibers and the matrix. ${ }^{41-43}$

Based on the structure, cleaning the surface of the fibers from a large number of impurities seems to be 


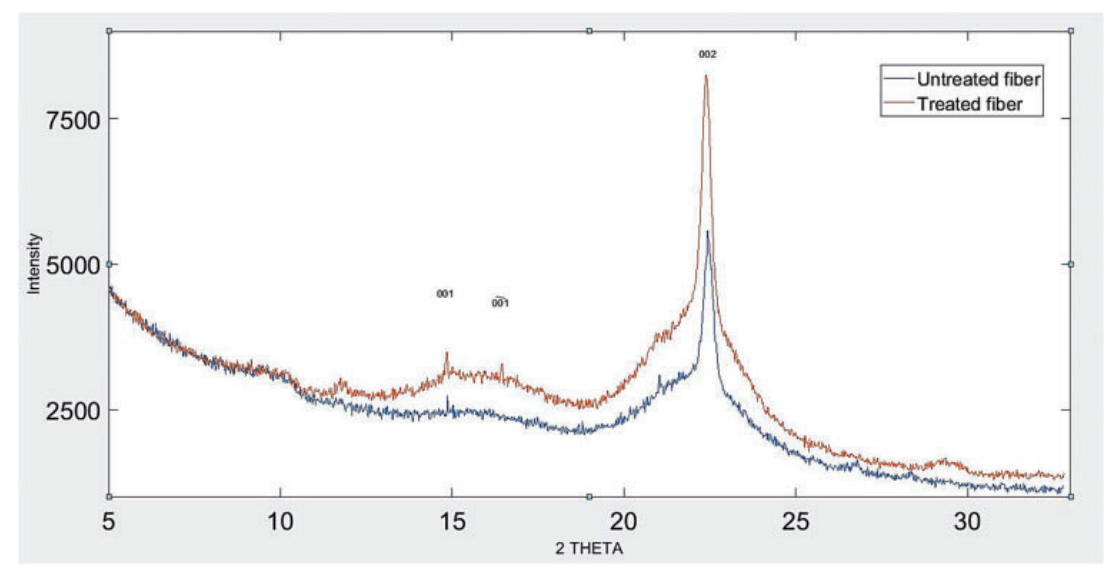

Figure 7. X-Ray diffractogram of Doum palm fiber.

Table 6. XRD diffraction of doum palm fiber.

\begin{tabular}{llll}
\hline & $\mathrm{I}_{0.02}\left(2 \theta=22.5^{\circ}\right)$ & $\mathrm{I}_{\mathrm{am}}\left(2 \theta=18.1^{\circ}\right)$ & $\begin{array}{l}\text { The crystallinity } \\
\text { index }(\%)\end{array}$ \\
\hline Untreated doum palm fiber & 5066 & 2163 & 57.30 \\
Treated doum palm fiber & 8430 & 2719 & 67.74 \\
\hline
\end{tabular}

(a)

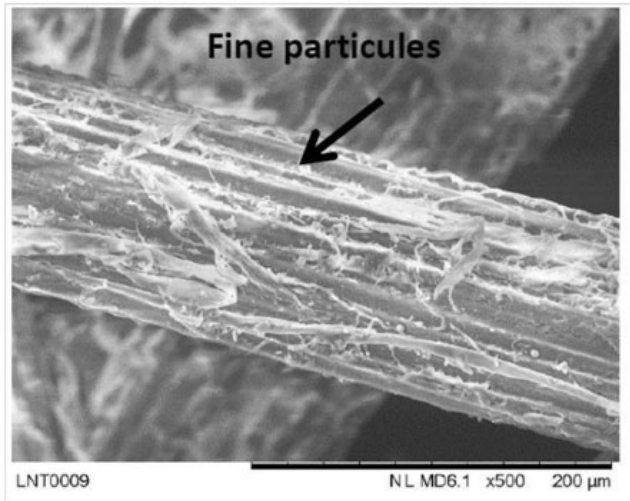

(b)

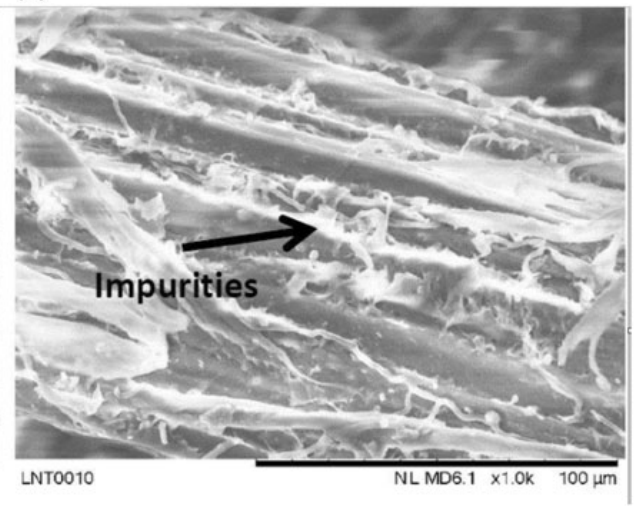

Figure 8. SEM image of untreated Doum palm fiber: (a) Magnificationx 500; (b) Magnificationx 000.
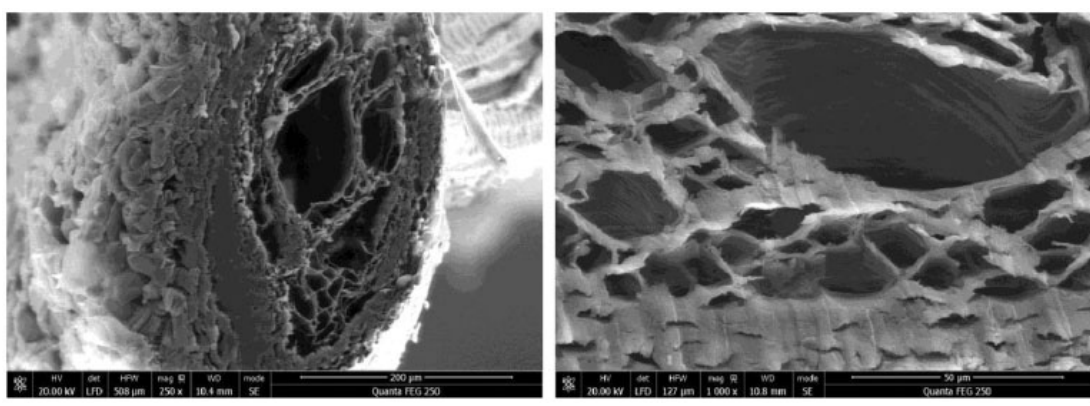

Figure 9. Cross-section of Doum palm fiber. 
crucial for overcoming the poor adhesion between the fibers and the matrix. These sightings confirm that the fiber structure is very important to have a good adhesion between Doum palm fibers and cement mortar. Thus, the Doum palm fiber could be good competitor for the development of a natural composite. ${ }^{39}$

The surface of raw Doum palm fibers is covered with a large number of amorphous materials predominantly composed of hemicellulose and lignin and other impurities (Figure 10). Raw Doum palm fibers are presented in Figure 10. Its surface is irregular and has many impurities and residual lignin. These impurities decrease the tensile properties of Doum palm fibers because they raise the diameter of the fiber without sustaining any tensile loads. Moreover, these impurities can cause an unstable adhesion between the fiber and the matrix and minimize the mechanical properties of the composites.

The use of alkali treatment removes the impurities and the fatty substance from the surface of the fiber and this decreases the fiber diameter as indicated in Figure 11.

The alkali treatment removes some lignin and hemicellulose and allows the fibrils to rearrange themselves, which leads to a better packing of cellulose chains.

Before treatment, the surface contains gummy and waxy substances as shown in Figure 10.
This component facilitates the extraction of fibers from the matrix but after treatment, the surface becomes much smoother without attacking cellulose microfibrils, which improves adhesion between the fibers and the cement matrix. ${ }^{36}$

\section{Effect of fiber length and alkali treatment on the composite mechanical properties}

Flexural strength. The flexural properties of composite reinforced with treated and untreated fibers are investigated by using a three-point bending test. The addition of fibers to specimens changes the flexural strength behavior of composite. It does not only improve the flexural strength but also improves their stiffness. Figure 12 shows the variation of the flexural strength of raw and alkali-treated Doum palm fiber reinforced cement mortars with the increase of fiber ratio (mass $\%$ ). As can be seen, the flexural strength of composite reinforced with treated Doum palm fibers is higher than that reinforced with untreated fibers. An important decrease of flexural strength by adding untreated Doum fiber compared to control mortar. This decrease is related to poor bonding between raw fiber and matrix due to the presence of amorphous materials on the fiber surface. The chemical treatment makes the fiber surface cleaner and rougher resulting in an (a)

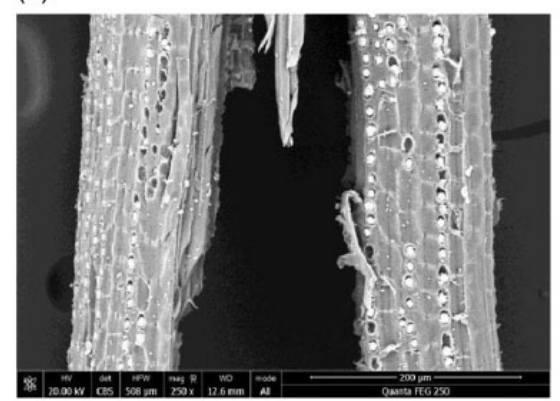

(b)

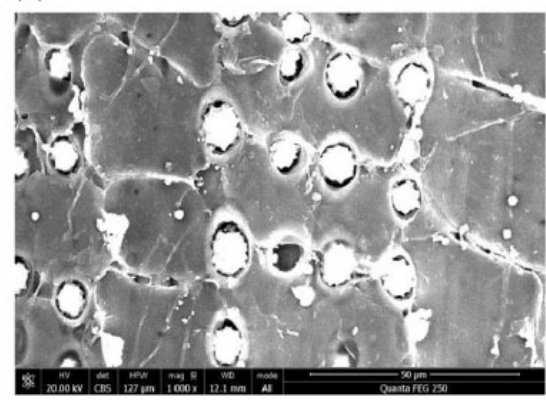

Figure 10. SEM micrographs of raw Doum palm fiber: (a) magnification $\times 250$; (b) magnification $\times 1000$.

(a)

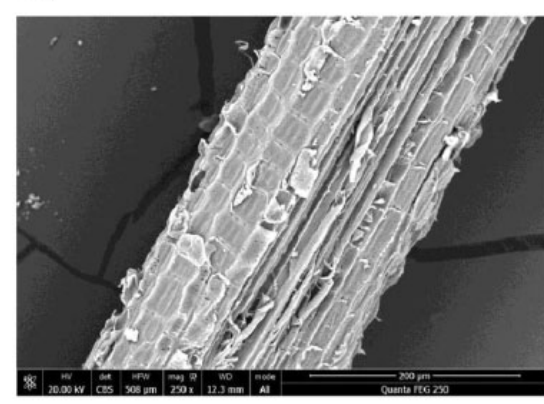

(b)

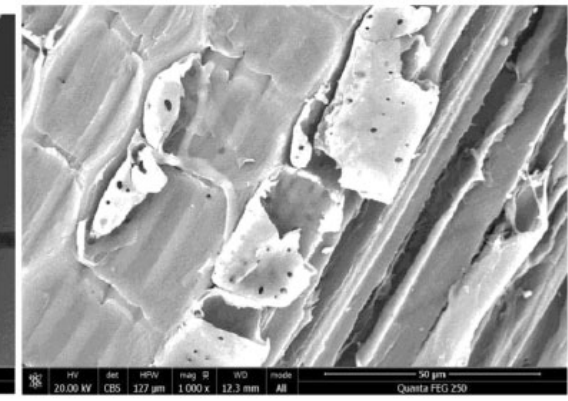

Figure I I. SEM micrographs of alkali treated Doum palm fiber: (a) magnification $\times 250$; (b) magnification $\times 1000$. 


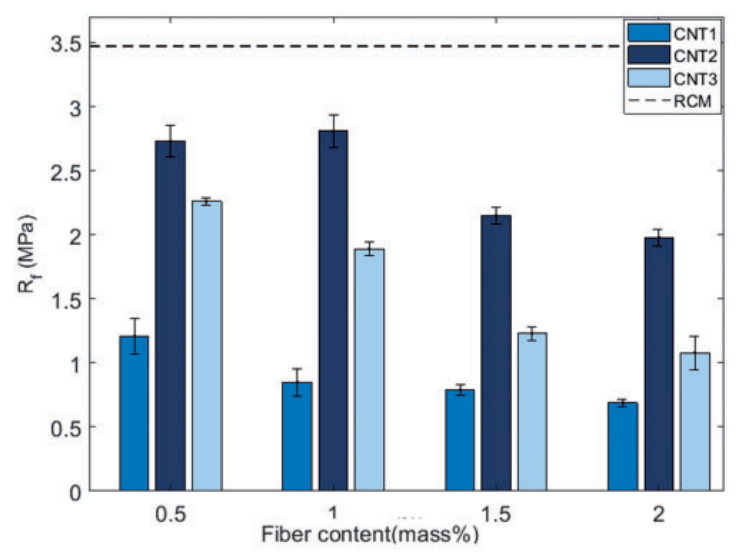

Figure 12. Flexural strength of raw Doum palm fiber reinforced cement mortar.

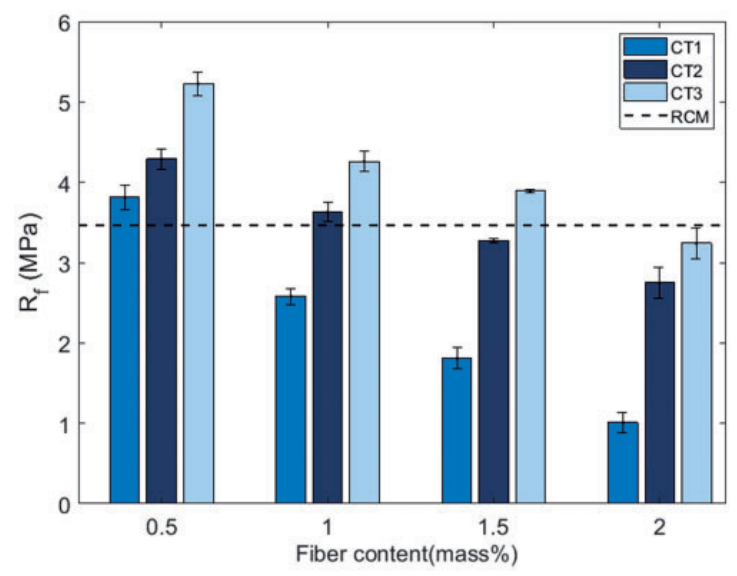

Figure 13. Flexural strength of treated Doum fiber reinforced cement mortar.

increase in the tensile strength of composite reinforced with treated fiber by improving the interfacial adhesion between the cementitious matrix and the fiber. ${ }^{39,40}$

Besides, untreated fibers have an important capacity to absorb water than treated fibers and they liberate it in the mortar after mixing. This behavior makes the composite more porous and contains a higher quantity of water than mortar reinforced with treated fibers and it decreases their flexural strength.

The flexural strength of composite reinforced with treated fiber firstly show an increase until an optimum value of fiber content and then a shortage with increasing fiber content. The flexural strength of control cement mortars is measured to be $3.47 \mathrm{MPa}$, whilst they are measured to be $5.22 \mathrm{MPa}, 4.29 \mathrm{MPa}$ and 3.81 MPa for respectively CT1, CT2, and CT3 with adding $0.5 \%$ of treated Doum palm fibers (figure 13 ). Such behaviour is essentially linked to the fiber bridging mechanism, which consists of transmitting supplementary tensile stress caused by Doumfiber through the crack surface and they limit the progression and the propagation of the crack, by a sewing effect, leading to increase the tensile strength of composite samples. The same results are obtained by previous research. ${ }^{44,45}$

The maximum flexural strength for the composite CT3 reinforced with a $0.5 \%$ mass fraction was $5.22 \mathrm{MPa}$.

Figure 14 presents flexural deflection curves for control cement mortar and cement mortars reinforced with treated Doum palm fiber. For the reference cement mortar (RCM), the curves are a linear brittle behavior. On the other hand, the curve of composite reinforced with treated Doum palm fiber (CT3) can be devised into three parts separated by two different force values. The post-peak response is controlled by the performance of the fibers while the pre-peak response is dominated by the performance of the matrix.

Control mortar reached a maximum load value of approximately $1400 \mathrm{~N}$ and then the load value dropped suddenly.the load value of Doum palm fiber reinforced mortar (CT3) exceeded $2400 \mathrm{~N}$, achieving a $70 \%$ strength increase.

The first region I present a linear evolution of the load versus, the first region presents a similar behavior that the control cement mortar, it is characterized by a linear evolution of the load versus deflection.

In region II, the first macroscopy damage in the material occurred with a notable change of the stiffness.

For the region, III a slow increase in load after the fibers took over because, after the peak, the response is controlled by the performance of the fibers. (Figure 14)

Compressive strength. The mean values obtained from the compression tests are presented in Figure 15 as a function of fibers content.

As expected, for all specimens reinforced with untreated fiber, the breakage decrease in proportion to the.amount of fiber present in the mixture. We can observe that.compressive strength is about $62 \%$ lower for samples CNT2 reinforced with.1.5\% of fiber,.in relation to the reference mortar. This behavior can be explained by the low surface protection in the fiber, which permits degradation due to the higher alkalinity of the matrix. This can adversely affect the adhesion between the cementitious matrix and fiber, producing spacing inside the mortar. These spaces reduce the compactness of the cement and consequently the compression strength of the reinforced mortars

A second source of the lower compressive strength of untreated fiber-reinforced mortar compared to control mortar was the bleeding which happens in a mortar with a higher water/cement ratio. Untreated fiber has high porosity, which means greater water absorption in its pores and they releases it when mixing the mortar. The same result is obtained by Orge ${ }^{46}$ and Orzekan. ${ }^{47}$ 

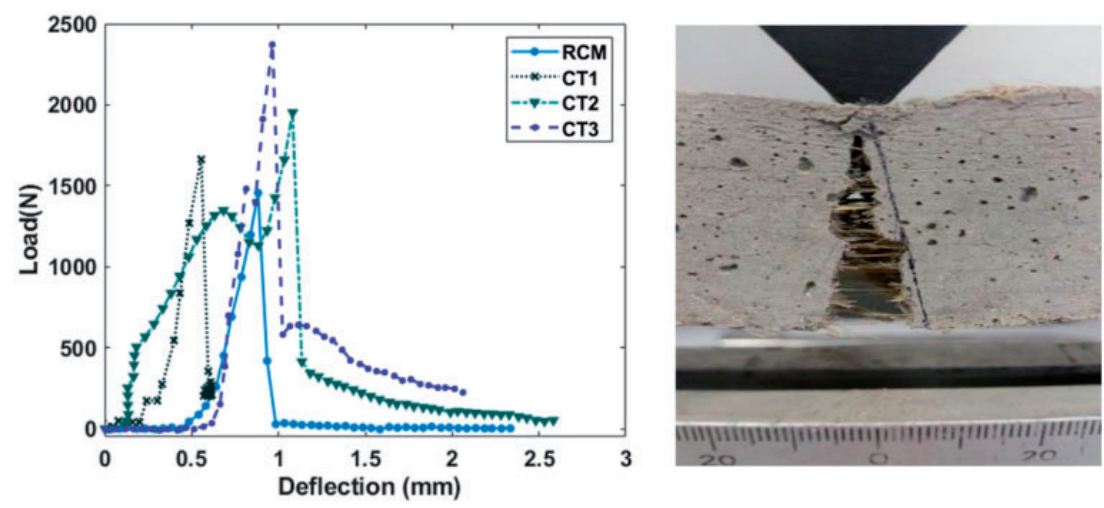

Figure 14. The load -deflection curve of control, treated Doum palm fiber reinforced cement mortar.

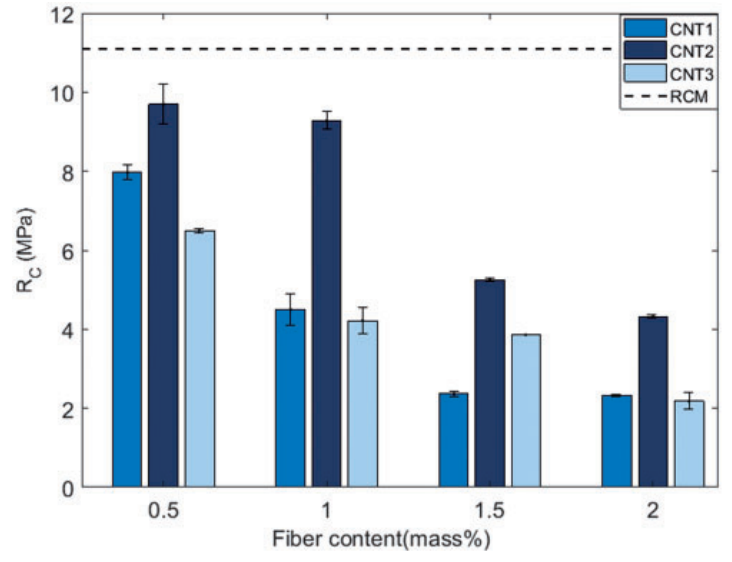

Figure 15. Compressive strength for raw Doum fiber reinforced cement mortar.

Contrarily, comparing the mechanical properties of control cement mortar and cement mortar reinforced with treated Doum palm fiber, a gain of compressive strength of about $18.63 \%$ for CT2 with $0.5 \%$ mass fraction can be observed (Figure 16). The maximum value is obtained for an optimum length and fiber content. Beyond this value, an incremental decrease of the material strength can be detected due to the non-homogenous mix and the higher quantities of the fiber-matrix interface. This decrease can be associated with an increase of porosity, the higher quantity of fiber make mixing difficult and aims to clump together, producing inadequate adhesion between the matrix and the fiber, which decreases the workability of fresh mortar and reduces their strength.

This result confirm what was found by Konin ${ }^{48}$ and khedari. ${ }^{49}$

\section{Fiber-matrix interaction}

The interface between the matrix and the fibers plays an important role in determining the mechanical properties of composites. Good interfacial bonding is

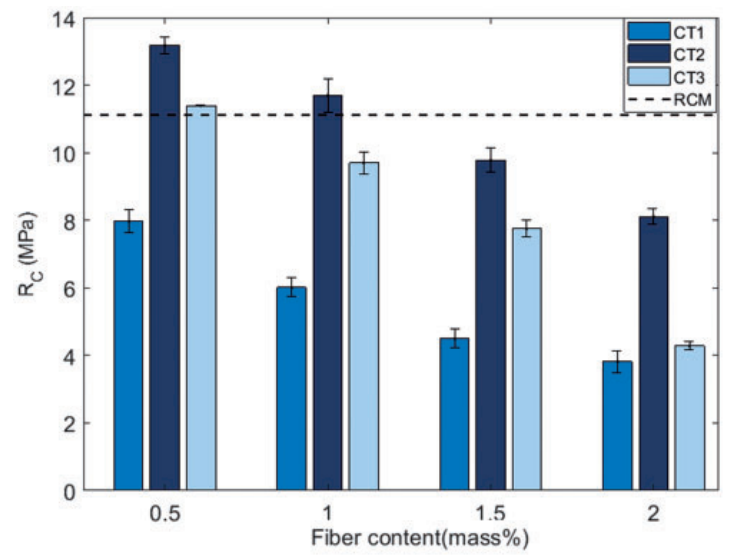

Figure 16. Compressive strength for treated Doum fiber reinforced cement mortar.

required to have a maximum reinforcement because the stress transferred between fiber and matrix passes through the interface.

Interfacial properties of Doum palm -cement mortar composites are investigated by digital microscope Leica DMS300 and HITACHI TM3030 scanning electron microscopy (SEM).

Figure 17 presents the broken surface of cement mortar reinforced with $0.5 \%$ of treated fiber (CT3). It demonstrates that the alkali-treated fiber is surrounded by the cement, proving a strong fiber-matrix adhesion. It also shows the existence of damage and cracks in the broken fiber ends due to the strong adhesion between the fibers and the matrix.

Composites prepared with treated fibers have a minimum pull out of the fiber, which reflects a better load transfer from the matrix to the fiber, and also an increase in the mechanical properties of the composites. The alkali treatment induced a better adhesion between fiber and matrix. The same results were obtained by Zukowski et al. ${ }^{23}$ 

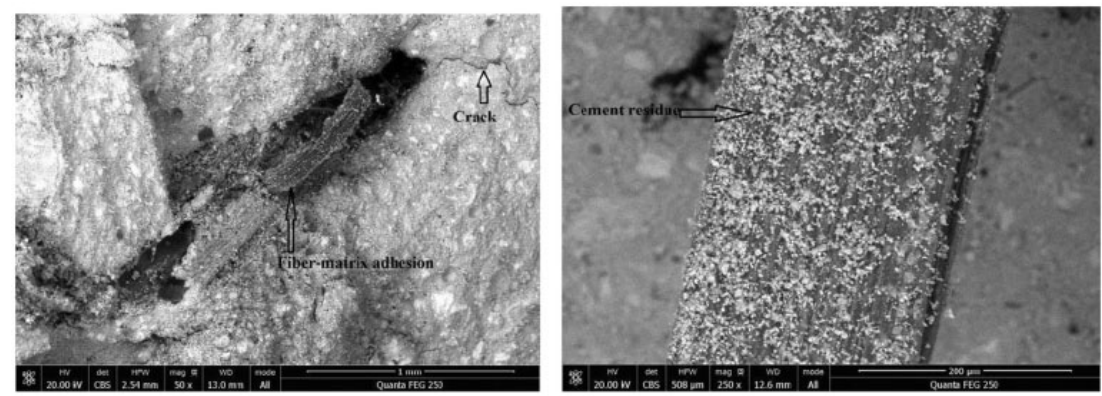

Figure 17. Break surface of cement mortar reinforced with treated fiber.
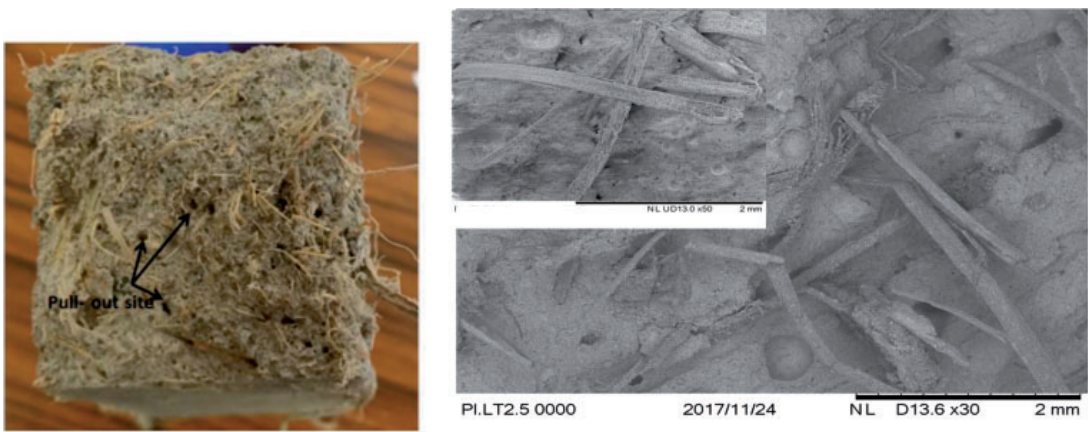

Figure 18. Break surface of cement mortar reinforced with untreated fiber.

While Figure 18 present cement mortar reinforced with $0.5 \%$ of untreated fiber (CT3). It shows that, the untreated fibers partly adhered to the matrix and pulled out from the matrix. After applying stress, several holes appears due to the debonding of the fiber from the matrix, which indicates a weak adhesion between the fiber and the matrix. This behavior has contributed to lower mechanical properties. However, for the composite reinforced with untreated Doum palm fibers, there is poor interaction between the fiber and the matrix, leading to a limited interfacial bonding and hence low mechanical properties.

\section{Effect of the fiber length and alkali treatment on the composite thermos-physical properties}

Thermal conductivity. The thermal conductivity is an important factor, which characterizes the effectiveness of the composite as a building material. Before testing, all specimens are dried at $105^{\circ} \mathrm{C}$ obtained a constant mass. The thermal properties are measured using the hot-disk method.

Figure 19 shows the influence of Doum palm fiber content on the thermal conductivity of the composite. As expected the thermal conductivity decreases as the fibers content increases.

While thermal conductivity of the control mortar is $(\mathrm{W} / \mathrm{m} \mathrm{K})$, it drops from $1 \mathrm{~W} / \mathrm{mK}$ to $0.36 \mathrm{~W} / \mathrm{mK}$ for $\mathrm{CT} 2$, which corresponds to a reduction of about
$64 \%$. This decrease is due to the increase of porosity of the dry mortars cause, by the high capacity of water absorption of Doum fiber. Furthermore, adding fiber into mortar increase the inner air of samples which make it more porous, the air has a lower thermal conductivity of about $0.026 \mathrm{~W} / \mathrm{mK}$ and it is lower than that of the solid material bringing to reduce the heat transfer, accordingly, the increase of the inner air of samples conducting to a decrease in thermal conductivity. The results following the observations reported in the literature. ${ }^{50,51}$

In general short fibers have too much difficult to align compared with the long fiber which creates a lot of voids leading to low thermal conductivity of specimen. ${ }^{39}$ In our case for particular fiber content, the thermal conductivity is lower for specimen CT2. However, the reduction of thermal conductivity values is important indicating that the use of Doum palm fiber has a positive effect.

Thermal diffusivity. First of all thermal conductivity is the rate at which heat flows through any kind of material, such as mortar. Thermal diffusivity, on the other hand, is the rate at which temperature changes occur in the mortar and it presents a major factor to estimate their potential as a good insulation material. It measures the rate of heat propagation through a material. 
Figure 20 presents the evolution of thermal diffusivity as a function of Doum palm fibers and for different size of fibers. It can be realized that all sizes of Doum palm fiber have a positive effect to amortize the heat diffusion in the composites. Indeed the incorporation of Doum palm fiber that the cement mortar reduces the thermal diffusivity of the composite. This is due to the opposition between the heat flow and the alveolar structure of fibers. ${ }^{52,53}$ According to these results, the optimal fibers content is 2\% and CT2 fibers because it has lower thermal diffusivity.

Thermo-mechanical diagram. Mechanical strength, thermal conductivity, and density are important parameters, which should be considered to select the greater building thermal insulating material. Compressive strength depends on the specimen density.

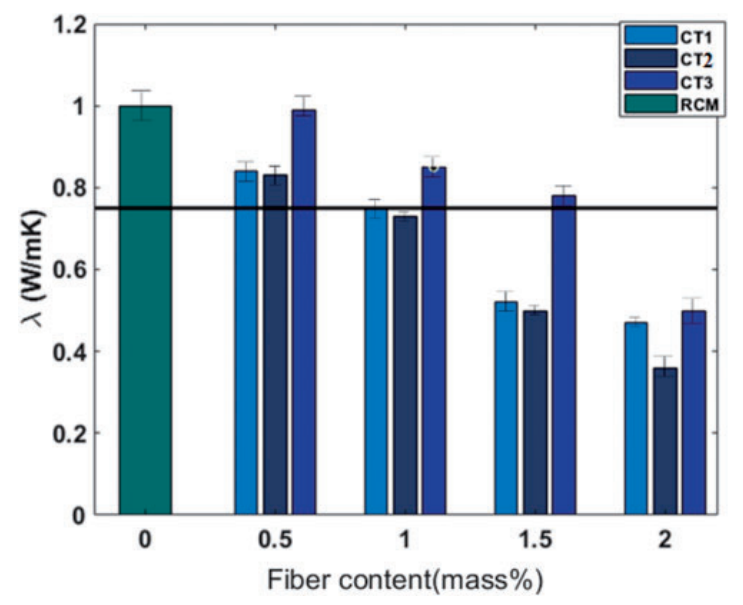

Figure 19. Thermal conductivity of composite as a function of fiber ratio.

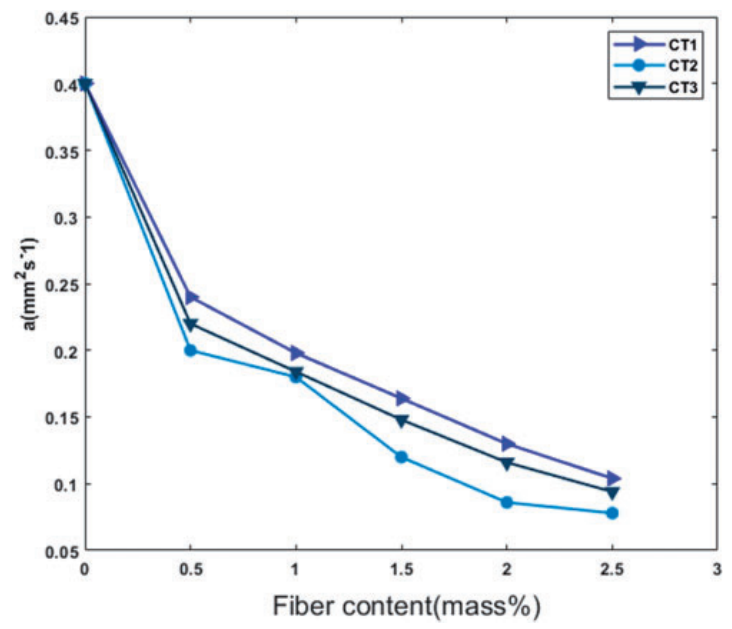

Figure 20. Thermal diffusivity as a function of fiber ratio.
Composite with lower density is considered as a lightweight material with a reduced thermal conductivity.

Thermo-mechanical diagram illustrates the relation between mechanical properties, thermal properties, and density. It permits the analysis of the thermosmechanical properties of thermal insulation materials.

Figure 21 presents the thermomechanical diagram of cement mortar reinforced with treated Doum palm fiber (CT2).

From Figure 21, by increasing Doum palm fiber ratio cement mortar becomes lighter and the thermal conductivity is meaningfully reduce. Indeed to obtain a composite with interesting thermal insulation capacity induces a detriment in the compressive strength.

The compressive strength raises suddenly from 11.11 MPa for reference composite to $13.18 \mathrm{MPa}$ for composites with a mass fraction of $0.5 \%$. Beyond this fiber fraction, the compressive strength of the composite decrease slightly to $7.8 \mathrm{MPa}$, which corresponds to $2.5 \%$ fiber content.

According to the functional classification of lightweight concrete conducted by Rilem ${ }^{8}$ and Boumhaout et al. ${ }^{1}$ are presented in Table 7 , the compressive strength of our composite is permissible for structure and insulating lightweight material.

Therefore, cement mortar composite reinforced with Doum palm fiber of fiber content below $0.5 \%$ for CT1 and CT2, for CT3 with fiber content more than $1.5 \%$, has a coherent thermal conductivity and mechanical properties with structural and insulating materials in buildings.

The test results of dry density, compressive strength, and thermal conductivity of mortar are summarized in Table 8 . The values were ranged from $1507-1812 \mathrm{~kg} / \mathrm{m}^{3}$ for dry density and $0.5-0.99 \mathrm{w} / \mathrm{m} . \mathrm{k}$ for thermal conductivity. The density of CT1 and CT3 mortars is slightly higher than CT2 mortar. As can be seen, the values of

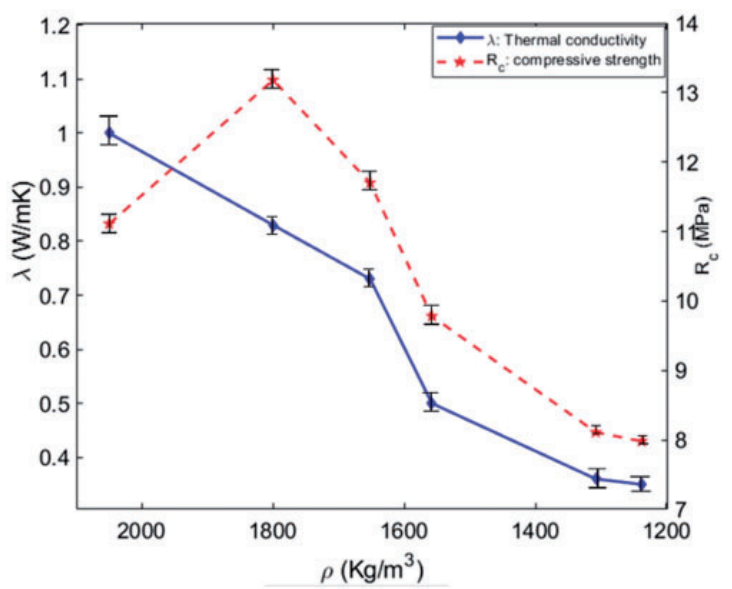

Figure $2 \mathbf{l}$. Compressive strength and thermal conductivity as a function of density. 
Table 7. Functional classification of light weight concrete. ${ }^{8}$

\begin{tabular}{|c|c|c|c|c|}
\hline & \multicolumn{2}{|c|}{ concrete of lightweight concrete } & \multicolumn{2}{|c|}{ Autoclaved aerated concretes } \\
\hline & $\begin{array}{l}\text { Class II (insulating and } \\
\text { construction) }\end{array}$ & $\begin{array}{l}\text { Class III } \\
\text { (insulating) }\end{array}$ & $\begin{array}{l}\text { Class II (insulating and } \\
\text { construction) }\end{array}$ & $\begin{array}{l}\text { Class III } \\
\text { (insulating) }\end{array}$ \\
\hline $\mathrm{R}_{\mathrm{C}}(\mathrm{MPa})$ & $>3.5$ & $>0.5$ & $>2.5$ & $>0.5$ \\
\hline$\lambda(\mathrm{W} / \mathrm{m} \cdot \mathrm{k})$ & $<0.75$ & $<0.3$ & $<0.75$ & $<0.3$ \\
\hline
\end{tabular}

Table 8. Composites properties.

\begin{tabular}{|c|c|c|c|c|c|c|c|c|c|}
\hline & & CTI & & & CT2 & & & CT3 & \\
\hline$\varphi(\%)$ & 0.5 & I & 1.5 & 0.5 & I & 1.5 & 0.5 & I & 1.5 \\
\hline $\mathrm{R}_{\mathrm{C}}(\mathrm{MPa})$ & 7.97 & 6.01 & 4.5 & 13.18 & 11.7 & 9.78 & 11.39 & 9.7 & 7.75 \\
\hline$\lambda(\mathrm{W} / \mathrm{m} \cdot \mathrm{k})$ & 0.84 & 0.75 & 0.52 & 0.83 & 0.73 & 0.50 & 0.99 & 0.85 & 0.78 \\
\hline$\rho(\mathrm{kg} / \mathrm{m} 3)$ & 1812 & 1683 & 1558 & 1800 & 1652 & 1507 & 1829 & 1750 & 1740 \\
\hline
\end{tabular}

thermal conductivity tends to decrease with a decrease in densities of mortars reinforced with Doumplam fiber. Moreover, the values of density of mortars reinforced with treated Doum fiber also decrease with the fiber content. These test results are in agreement with those obtained by other research work. ${ }^{49}$ Khedari et al. $^{49}$ study the thermal conductivity of cement mortar reinforced with coconut fiber and explaine that the density tended to decrease with the fiber mass fractions because fibers clumped together during mixing, capturing water-filled spaces that successively turn into porosities or air voids.

\section{Conclusion}

This paper highlights the potential behind using Doum palm fiber in structural and insulation cement mortar mixes.

The problem of biodegradability of natural fibres was investigated in this study. An alkaline treatment of fibers with a $1 \%$ concentration $\mathrm{NaOH}$ solution combined with sodium hypochlorite $(\mathrm{NaOCl})$ was performed. The results obtained from X-ray diffraction (DRX), infrared spectroscopy (FTIR) and scanning electron microscope observation show that this treatment is effective in removing amorphous materials such as lignin and hemicellulose, increasing the crystallineity of the fiber leading to greater mechanical properties which leads to an improvement in adhesion between cement and fibers.

It is generally seen that the introduction of raw fiber into cement mixes causes a decrease in flexural and compressive strength due to the poor bond between fiber and matrix.
When failure propagates inside the cement mixes in tension, the poor bond around fibers leads to decrease flexural and compressive strength.

A notable improvement of the thermal properties of cement mortars reinforced with Doum palm fiber is observed as compared to reference cement mortar.

In addition, the density, and thermal conductivity decrease by increasing fiber ratio into the composite, while the obtained values reveal that adding $1 \%$ of CT2 fibers results composite with $\rho=1652 \mathrm{kgm}^{-1}$ and $\lambda=0.73 \mathrm{~W} / \mathrm{m} . \mathrm{k}$. These gotten values following the Rilem recommendation for insulating material.

The most important conclusions are the following:

1. Taking into account the results obtained in 'Results and discussions' section, comparing treated and raw doum fiber composites, there is a significant improvement with the treated fibers. It is now possible to exclude the incorporation of raw fibres with a cement binder, because of the presence of amorphous materials that lead to poor hydration of the fibers with the cement binder.

2. Adding $1 \%$ of $\mathrm{CT} 2$ results in a considerable improvement in the mechanical properties of the cement mortar. The 28 days flexural and compressive strength of CT2 are $23.6 \%$ and $18.63 \%$ respectively superior to the control mortar. Revenge, the 28 days compressive strength of the other composite still complies with the strength requirement for lightweight concrete.

3. Adding, treated Doum palm fiber to cement mortar trained in changing the failure mode of the composite. The flexural test reveals that the reinforced specimens have a ductile mode with a minimizing of the failure propagation by fibers. 
4. The thermal conductivity and the density are meaningfully (on average $26.22 \%$ and $27 \%$, respectively) lower than control mortar.

\section{Declaration of Conflicting Interests}

The author(s) declared no potential conflicts of interest with respect to the research, authorship, and/or publication of this article.

\section{Funding}

The author(s) received no financial support for the research, authorship, and/or publication of this article.

\section{ORCID iD}

Fatma Naiiri (D) https://orcid.org/0000-0003-3378-8933

\section{References}

1. Boumhaout M, Boukhattem L, Hamdi $\mathrm{H}$, et al. Thermomechanical characterization of a bio-composite building material: mortar reinforced with date palm fibers mesh. Constr Build Mater 2017; 135: 241-250.

2. Panyakaew $\mathrm{S}$ and Fotios S. New thermal insulation boards made from coconut husk and bagasse. Energy Build 2011; 43: 1732-1739.

3. Wei $\mathbf{J}$ and Meyer C. Degradation mechanisms of natural fiber in the matrix of cement composites. Cem Concr Res 2015; 73: 1-16.

4. Benmansour N, Agoudjil B, Gherabli A, et al. Thermal and mechanical performance of natural mortar reinforced with date palm fibers for use as insulating materials in building. Energy Build 2014; 81: 98-104.

5. Agoudjil B, Benchabane A, Boudenne A, et al. Renewable materials to reduce building heat loss: characterization of date palm wood. Energy Build 2011; 43: 491-497.

6. Chikhi M, Agoudjil B, Boudenne A, et al. Experimental investigation of new biocomposite with low cost for thermal insulation. Energy Build 2013; 66: 267-273.

7. Savastano H, Warden PG and Coutts RSP. Brazilian waste ${ }^{\circledR}$ bres as reinforcement for cement-based composites q. Cem Concr Compos 2000; 22: 379-384.

8. RILEM: Functional classifcation of lightweight concretes. Mater. Struct 1978; 11: 281-282.

9. Savastano H, Santos SF, Radonjic M, et al. Fracture and fatigue of natural fiber-reinforced cementitious composites. Cem Concr Compos 2009; 31: 232-243.

10. Savastano H Jr, Warden PG and Coutts RSP. Potential of alternative fibre cements as building materials for developing areas. Cem Concr Compos 2003; 25: 585-592.

11. Savastano J, Warden PG and Coutts RSP. Ground iron blast furnace slag as a matrix for cellulose-cement materials. Cem Concr Compos 2001; 23: 389-397.

12. Ramakrishna G and Sundararajan T. Impact strength of a few natural fibre reinforced cement mortar slabs: a comparative study. Cem Concr Compos 2005; 27: 547-553.
13. Mansur M. a and Aziz M. a. A study of jute fibre reinforced cement composites. Int J Cem Compos Light Concr 1982; 4: 75-82.

14. Aziz MA, Paramasivam P, Lee SL. Prospects for natural fibre reinforced concretes in construction. Int $\mathrm{J} \mathrm{Cem}$ Compos Lightweight Concr 1981; 3: 123-32.

15. Z. R. Lopičić et al., Effects of different mechanical treatments on structural changes of lignocellulosic waste biomass and subsequent $\mathrm{Cu}(\mathrm{II})$ removal kinetics. Arab. J. Chem. 2019; 12(8): 4091-4103.

16. Kabir MM, Wang H, Lau KT and Cardona F. Chemical treatments on plant-based natural fibre reinforced polymer composites: An overview. Compos. Part B Eng. 2012; 43(7): 2883-2892.

17. Oudiani AE, Chaabouni Y, Msahli S, et al. Crystal transition from cellulose I to cellulose II in $\mathrm{NaOH}$ treated Agave americana L. fibre. Carbohydr Polym 2011; 86: 1221-1229.

18. Raj G, Balnois E, Baley C, et al. Role of polysaccharides on mechanical and adhesion properties of flax fibres in flax/PLA biocomposite. Int J Polym Sci 2011; 2011: 1-11.

19. Saha P, Manna S, Chowdhury SR, et al. Enhancement of tensile strength of lignocellulosic jute fibers by alkali-steam treatment. Bioresour Technol 2010; 101: 3182-3187.

20. Shalwan A and Yousif BF. Investigation on interfacial adhesion of date palm/epoxy using fragmentation technique. Mater Des 2014; 53: 928-937.

21. Tolêdo Filho RD, Scrivener K, England GL, et al. Durability of alkali-sensitive sisal and coconut fibres in cement mortar composites. Cem Concr Compos 2000; 22: 127-143.

22. Fantilli AP, Sicardi S and Dotti F. The use of wool as fiber-reinforcement in cement-based mortar. Constr Build Mater 2017; 139: 562-569.

23. Zukowski B, de Andrade Silva F and Toledo Filho RD. Design of strain hardening cement-based composites with alkali treated natural curauá fiber. Cem Concr Compos 2018; 89: 150-159.

24. Fan YH, Gharpuray LT and Lee MM. Biotechnology monographs - cellulose hydrolysis. Tep Apx 1988; 60: 27-30.

25. Fatma N, Lamis A, Salem M, Zitoune R and Mondher $Z$. The effect of doum palm fibers on the mechanical and thermal properties of gypsum mortar. J. Compos. Mater. 2019; 53(19): 2641-2659.

26. ASTM C1329 - 05. Standard Specification for Mortar Cements. ASTM C1329 - 05, Annu book ASTM Stand 04.01 .

27. ASTM C348. Standard test method for flexural strength of hydraulic-cement mortars. ASTM C348-02, Annu book ASTM Stand 04.01.

28. Mishellany A, Delalande G and Toureng C. La normalisation des granulats et l'Europe 1998; 216.

29. Van Soest PJ and Wine RH. Use of Detergents in the Analysis of Fibrous Feeds. IV. Determination of Plant Cell-Wall Constituents. J. AOAC Int. 1967; 50(1): 50-55.

30. Creely JJ and Conrad M. Empirical Method for Estimating the Degree of Crystallinity of Native 
Cellulose Using the X-Ray Diffractometer. Text. Res. J. 1958; 29(10): 786-794.

31. Roncero MB, Torres AL, Colom F and Vidal T. The effect of xylanase on lignocellulosic components during the bleaching of wood pulps. Bioresour. Technol 2005; 96 (1): 21-30.

32. EN1015-11: Methods of test for mortar for masonry. Part 11. Determination of flexural and compressive strength of hardened mortar. Denmark: DS, 2000.

33. ASTM. Standard test methods for physical testing of gypsum, gypsum plasters and gypsum. vol. 99. West Conshohocken: ASTM, 2015, pp. 1-8.

34. Hamza S, Saad H, Charrier B, et al. Physico-chemical characterization of Tunisian plant fibers and its utilization as reinforcement for plaster based composites. Ind Crops Prod 2013; 49: 357-365.

35. Salit MS, Ishak MR and Aziz NA. Selecting Natural Fibers for Bio-Based Materials with Conflicting Criteria. Am. J. Appl. Sci. 2015; 12(1): 64-71.

36. Li X, Tabil LG and Panigrahi S. Chemical treatments of natural fiber for use in natural fiber-reinforced composites: a review. J Polym Environ 2007; 15: 25-33.

37. Thygesen A, Oddershede J, Lilholt H, Thomsen AB and Sta K. On the determination of crystallinity and cellulose content in plant fibres. Cellulose 2005: 12(6): 563-576.

38. Wang B, Sain M and Oksman K. Study of Structural Morphology of Hemp Fiber from the Micro to the Nanoscale. Appl. Compos. Mater. 2007; 14: 89-103.

39. Hammami A. Date palm fibers as polymeric matrix reinforcement: Fiber characterization. Polym. Compos. 2005; 26(4): 486-497.

40. Kriker A. Mechanical properties of date palm fibres and concrete reinforced with date palm fibres in hot-dry climate. Cem. Concr. Compos. 2005: 27(5): 554-564.

41. Rout J, Misra M, Tripathy SS, Nayak SK and Mohanty AK. Surface Modification of Coir Fibers . II . Cu ( II )IO 4 Initiated Graft Copolymerization of Acrylonitrile onto Chemically. J. Appl. Polym. Sci. 2002; 84(1): 2-4.

42. Cao Y, Shibata S and Fukumoto I. Mechanical properties of biodegradable composites reinforced with bagasse fibre before and after alkali treatments. Compos Part $A$ Appl Sci Manuf 2006; 37: 423-429.

43. Sedan D, Pagnoux C, Smith A and Chotard T. Mechanical properties of hemp fibre reinforced cement: Influence of the fibre / matrix interaction. J. Eur. Ceram. Soc. 2008; 28(1): 183-192.

44. Xie X, Zhou Z, Jiang M, et al. Cellulosic fibers from rice straw and bamboo used as reinforcement of cementbased composites for remarkably improving mechanical properties. Compos Part B 2015; 78: 153-161.

45. Khorami M and Ganjian E. Comparing flexural behaviour of fibre-cement composites reinforced bagasse: wheat and eucalyptus. Constr Build Mater 2011; 25: 3661-3667.

46. Sarikanat M and Demirci C. Composites: Part B Physical and mechanical properties of randomly oriented coir fiber - cementitious composites. Compos. Part B Eng. 2014; 61: 49-54

47. Ozerkan NG, Ahsan B, Mansour S, et al. Mechanical performance and durability of treated palm fiber reinforced mortars. Int J Sustain Built Environ 2013; 2: 131-142.

48. Konin A. Effect of the type of binder on physicomechanical and thermal properties of mortars with a basis of coir. ARPN J Eng Appl Sci 2012; 7: 277-282.

49. Khedari J, Suttisonk B, Pratinthong N, et al. New lightweight composite construction materials with low thermal conductivity. Cem Concr Compos 2001; 23: 65-71.

50. Abani S, Hafsi F, Kriker A, et al. Valorisation of date palm fibres in Sahara constructions. Energy Procedia 2015; 74: 289-293.

51. Berrehail T, Zemmouri $\mathrm{N}$ and Agoudjil B. Thermal Conductivity of Cement Stabilized Earth Bricks Reinforced with Date Palm Fiber. AIP Conf. Proc. 2018: 1968(1): 030036.

52. Ouajai S and Shanks RA. Composition, structure and thermal degradation of hemp cellulose after chemical treatments. Polym. Degrad. Stab. 2005; 89(2): 327-335.

53. Agoudjil B, Benchabane A, Boudenne A, et al. Renewable materials to reduce building heat loss : characterization of date palm wood. 2011; 43: 491-497. 